\title{
Other Innovation Policies and Alternative Modelling Approaches
}

\author{
Cristiana Benedetti Fasil, Giammario Impullitti, \\ and Miguel Sanchez-Martinez
}

\subsection{INTRODUCTION}

This chapter contains a thorough discussion of the results of two simulation exercises on the macroeconomic implications of changes in entry barriers and R\&D tax credits, assessed using the QUEST III model. ${ }^{1}$ Next we provide a brief introduction to the policy context and relevance

1 The discussion on this chapter draws from Benedetti Fasil et al. (2017) and SanchezMartinez et al. (2017).

C. Benedetti Fasil (Deceased) - M. Sanchez-Martinez ( $\varangle)$

European Commission, DG JRC, Brussels, Belgium

e-mail: miguel.sanchez-martinez@ec.europa.eu

C. Benedetti Fasil (Deceased)

e-mail: cristiana.benedettifasil@ec.europa.eu

G. Impullitti

University of Nottingham, Nottingham, UK

e-mail: Giammario.Impullitti@nottingham.ac.uk

(C) The Author(s) 2022

U. Akcigit et al. (eds.), Macroeconomic Modelling of ReD D

and Innovation Policies, International Economic Association Series, https://doi.org/10.1007/978-3-030-71457-4_9 
of these two types of innovation-related issues, before proceeding to the technical discussion of the results in the next section.

Entry barriers play a key role in business dynamism by conditioning the flow of entry of new firms into markets and the transformation of new ideas into marketable products. These processes lie at the core of economic and productivity growth through the reallocation of resources from shrinking and exiting firms to new entrants and growing firms. ${ }^{2,3} \mathrm{~A}$ study from the European Commission covering France, Italy, Germany, Ireland, Portugal and Spain over the 1997-2003 period, estimated that a $1 \%$ increase in the entry rate of firms would increase GDP growth by $0.6 \%$ and employment growth by $2.67 \%$ based on data from the same period. ${ }^{4}$

Following the launch of the Lisbon Strategy, most Member States began to reduce the costs of starting a business. ${ }^{5}$ Nevertheless, the levels of entry barriers are still very heterogeneous across Member States and some countries, such as Italy, Cyprus, Malta and Poland, face costs to start a business that are, relative to income per capita, up to 70 times higher than the best EU performers, namely Denmark, United Kingdom and Ireland (Ciriaci, 2014, Table III.1). The OECD's indicator on product market regulation also provides evidence of country heterogeneity in terms of barriers to entrepreneurship (OECD, 2015). Over time, most countries have made considerable progress in removing entry barriers, although this pace has slowed down since 2008. Hence, in several Member States policymakers still have room for significant interventions directed towards creating more dynamic and competitive industries. As a result, policies in favour of Small- and Medium-sized Enterprises (SMEs),

2 Nicoletti and Scarpetta (2003) using a panel of 18 OECD countries between 1984 and 1998, were the first to estimate that lower entry barriers would result in a faster catch up with the technology frontier. This is now widely established in the empirical literature.

${ }^{3}$ Several papers assess the growth contribution of the reallocation of resources from exiting to entering firms. For instance, Luttmer (2007) and Gabler and Licandro (2009) estimate that this selection effect can explain between $20 \%$ and $50 \%$ of US GDP growth. These estimates are consistent with Scarpetta et al. (2002), who find that entry and exit contributed to between $20 \%$ and $40 \%$ of aggregate productivity growth in a panel of OECD countries.

${ }^{4}$ See Cincera and Galgau (2005).

5 See Ciriaci (2014, Table III.2). The World Bank definition of the costs of starting a business comprises three main elements; the number of procedures, the number of days and the cost as percentage of income per capita necessary to start a business. These are the so-called red tape entry barriers 
in particular those policies that may create the right conditions for the flourishing of the so-called High Growth Innovative Enterprises (HGIE) are receiving greater attention. An important, related policy issue is to understand and measure the impact of policies aimed at reducing entry barriers. ${ }^{6}$ Both large companies and SMEs are bound to benefit from a reduction in entry barriers. However, large companies are often better able to cope with entry barriers than SMEs due to having access to a larger pool of resources, including easier access to finance. Consequently, policies aimed at a reduction of entry barriers notably support SMEs and, in particular, young enterprises, as these are the types of firms most negatively affected by entry barriers. This is a particularly important policy issue in order to increase productivity and employment growth, as most of the job creation by young firms is carried out by new firms entering the market (Haltiwanger, 2013). Criscuolo et al. (2014) in a study with 18 OECD countries estimate that the share of total employment creation due to SMEs that are less than three years old is disproportionately larger relative to their size.

Firm size is also closely related to business dynamism. The European Commission's Product Market Review (European Commission, 2013) highlights a non-linear relationship between firm size at both entry and exit and an efficient allocation of resources between and within firms. In particular, they find that, on average, an increase in the size of a firm by just one employee, when entering the market, is associated with an increase in efficiency by $1.6 \%$. In addition, such a relation exhibits an inverted U-shape, peaking at 10 employees at entry. This indicates that policies geared toward increasing the average size of small start-ups give rise to efficiency gains.

Concerning fiscal incentives to promote R\&D investment, 25 Member States currently employ some form of tax break instruments, as a means to ultimately support economic growth and employment. Strong commitment for public intervention to spur investment in R\&D can be traced back to the 2003 action plan 'Investing in Research', whereby the European Commission recommended supporting private investments in research. In particular, concerning tax measures, it recommended to improve fiscal measures for research on the basis of formal evaluations,

${ }^{6}$ At the European level, Sapir (2004) stressed that too much policy attention is paid to incumbent firms to ensure fair competition, whereas entrants and young firms tend to be neglected. 
mutual learning and the application of principles of good design such as simplicity, low administrative cost and stability' (European Commission, 2003).

Some Member States such as France were already making use of R\&D tax credits at the time of the action plan, but this recommendation was subsequently adopted by many others, making tax credits a widely used instrument in the EU as a way to subsidise the conduct of $\mathrm{R} \& \mathrm{D}$. The total amount of foregone tax revenue due to R\&D tax breaks is estimated at more than EUR 12 billion (OECD, 2014). In some countries, such as Belgium and France, the total value of foregone tax revenue via tax credits is higher than the value of government direct expenditures on R\&D subsidies.

Despite the increasing relevance of tax credits as a stimulus tool for $\mathrm{R} \& \mathrm{D}$ investment in the EU, ex-ante evaluations of their potential macroeconomic effects are scarce. In particular, studies in the same vein as the one presented below do not provide an investigation of the structural factors behind the observed cross-country differences in the impact of R\&D tax credits on macroeconomic outcomes. As noted in Veugelers (2016), 'where the macro models are as yet underexploited and where they would be a very useful R\&D policy instrument is in assessing which framework conditions need to be in place to improve the impact of public R\&D funding instruments, such as grants and tax credits'.

The next sections provide a summary of two exercises that focus precisely on tackling this last point by providing insights on the structural factors of EU Member States that condition the macroeconomic effects of policies addressed at lowering entry barriers and increasing fiscal incentives for R\&D investment, respectively. In the final section, possible complementary refinements and extensions to these two analyses are discussed at a technical level.

\subsection{The Macroeconomic Impact of Entry Barriers and R\&D Tax Credits}

This section, building on the content of Chapter 5 , presents and discusses two examples of policy shock simulations undertaken using the QUEST III model: (i) a reduction equal to $0.1 \%$ of GDP in entry barriers for intermediate firms (see Benedetti Fasil et al., 2017) and (ii) a $0.1 \%$ increase of GDP in tax-credited R\&D investment (see Sanchez-Martinez et al., 2017). 
In this literature, and in the specific case of QUEST III, entry barriers are treated as sunk costs paid by intermediate firms upon entry, while tax credits impact directly on the user cost of intangible capital. Intuitively, the general mechanism through which these policies propagates in the model's economy is the following: a reduction in entry barriers or an increase in tax credits stimulate entry in the intermediate good sector and the demand for new patents. This leads to a gradual increase in R\&D activities, resulting in the production of more patents, which can be used to develop new product lines. On the labour market, this is accompanied by a reallocation of high-skilled workers from the production to the research sector due to increased demand for this type of workers in the latter. If the drain of high-skilled workers from the final good sector to the R\&D sector is sufficiently large, final good-producing firms might reduce output even if they increase hiring of low- and medium-skilled workers. Indeed, because of the reallocation of high-skilled workers, the initial effects on GDP can be positive or negative depending, among other things, on the elasticity of substitution among the different types of labour. Nevertheless, the size of these effects is small in the short term. Substantial, positive output effects materialise in the longer term, once R\&D activities yield their fruits in the form of marketable products. Despite the increase in the efficiency of all factors of production in all countries, brought about by the higher stock of ideas, employment (at all skill levels) is higher in the new equilibrium. This is due to the surge in aggregate demand ensuing from higher incomes for households, which more than compensates for the labour-saving effect of the increase in TFP.

The key equation behind the aforementioned mechanism is the free entry condition of intermediate firms. ${ }^{7}$ That is,

$$
P R_{x, t}=\frac{i_{A, t} P_{A, t}}{D E F_{t}}+F C_{A}\left(i_{A, t}+C_{A, t}\right)
$$

where $F C_{A}$ represents the level of entry costs, $P R_{x, t}$ is the profit earned by design/firm $x, P_{A, t}$ is the price for licencing a patent, $D E F_{t}$ is the GDP deflator, and $i_{A, t}$ represents the user cost of intangible capital. ${ }^{8}$

${ }^{7}$ Free entry means that intermediate firms will enter the market and thus buy new patents until the value of profits in a given period equals the entry costs plus the net value of patents.

${ }^{8} C_{t}^{A}$ is an auxiliary term related to the change of the price of patents over time. 
While fixed entry costs enter this equation directly, tax credits do so indirectly via $i_{A, t}$.

This equilibrium equation shows that high entry barriers or low R\&D tax credits (i.e., high cost of intangible capital) must be compensated for by high expected profits or by a lower licencing price for the patent, or by a combination of both, for the decision to enter the market to be economically sensible. The profits of intermediate firms are positively related to the inverse of the mark-up charged by final good producers, $\eta_{y, t}$, and negatively related to the number of patents issued, $A_{t}$ :

$$
\begin{aligned}
P R_{x, t} & =\left(\frac{1-\theta}{\theta}\right) \frac{i_{k, t} P_{C, t} x_{t}}{D E F_{t}}=(1-\theta) \frac{p_{x, t} x_{t}}{D E F_{t}} \\
& =(1-\theta) \frac{\eta_{y, t}(1-\alpha)\left(Y_{t}+F C_{Y}\right)}{A_{t} D E F_{t}}
\end{aligned}
$$

where $\theta$ is the elasticity of substitution between intermediate good inputs in the final good production function, $\alpha$ is the fixed-cost-adjusted elasticity of labour in final good technology, $Y_{t}$ is aggregate output from the final good sector, $F C_{Y}$ are fixed costs in final good production, $i_{k, t}$ is the user cost of tangible capital, $P_{C, t}$ is the price index of final goods. As each intermediate firm buys only one patent to produce one intermediate product, the number of patents equates the number of intermediate firms and represents, together with the mark-up, a measure of market competition. Hence, the more concentrated markets are, the higher the profits for each intermediate producer.

The price of patents, determined optimally in the R\&D sector, is positively related to the unit labour cost of researchers and inversely related to the elasticity of $R \& D$ output with respect to research labour, $\lambda$ :

$$
P_{t}^{A}=\frac{D E F_{t}}{\lambda} \frac{W_{H, t} L_{A, t}}{\Delta A_{t}}+M A D J_{t}
$$

Substituting 9.2, 9.3 and 6.18 into 9.1, we can rewrite the latter as follows

$$
\begin{aligned}
(1-\theta) \frac{\eta_{y, t}(1-\alpha)\left(Y_{t}+F C_{Y}\right)}{A_{t} D E F_{t}} & =i_{t}^{A}\left(\frac{W_{H, t} L_{A, t}}{\lambda \nu A_{t-1}^{\varphi} L_{A, t}^{\lambda}}+\frac{M A D J_{t}}{D E F_{t}}\right) \\
& +F C_{A}\left(i_{A, t}+C_{A, t}\right)
\end{aligned}
$$


A decrease in the user cost of intangible capital drives an initial positive wedge between period profits and entry costs, attracting new firms into the sector until profits are driven down to exactly match costs, so that no more profits from arbitrage can be realised. This implies that, in countries with relatively high capital income taxes, a reduction in the user cost of capital alleviates the costs faced by intermediate good firms to a greater extent than in countries with lower tax rates, fostering the creation of new intermediate businesses and thus more purchases of patents from households.

In fact, it can be shown that the impact of an increase in the R\&D tax credit rate on the user cost of intangible capital increases with the level of the (tangible) capital income tax rate. This can be seen algebraically from the equilibrium condition of the user cost of R\&D capital:

$$
\begin{aligned}
i_{A, t} & =\frac{\left(1-\tau_{A}\right)\left(1+i_{t}-\left(1+g_{P_{A}}\right)\left(1+\pi_{A, t+1}\right)\left(1-\delta_{A}\right)\right)-t_{K} \delta_{A}}{1-t_{K}} \\
& +r p_{A, t}+\epsilon_{t}^{r p_{A}}
\end{aligned}
$$

where $\tau_{A}$ represents the $\mathrm{R} \& \mathrm{D}$ tax credit rate and $t_{K}$ is the capital income tax rate. This equation has an intuitive interpretation, as it shows that the user cost of capital depends, among other things, negatively on the tax credit rate and positively on the risk premium demanded by capital owners, $r p_{A, t}$, the risk-free interest rate and the rate at which the stock of ideas depreciates, $\delta^{A}$. Moreover, it can be shown that a higher capital income tax rate in a given country means that hiring either type of capital in the economy is more expensive than in other countries. Thus, a decline in the user cost of capital leads to a proportionally higher demand for patent licences arising from intermediate good firms (see Sanchez-Martinez et al., 2017).

\subsubsection{Simulation Results}

Before presenting delving into the simulation exercises, the reader should be aware of a number of caveats. First, the current version of QUEST III models innovation exclusively via the patents generated by R\&D efforts. Thus, it does not account for investments and innovations which do not result in patents. This is a somewhat limited view of both R\&D and innovation. Second, for relatively long time horizons, the simulations are likely 
to underestimate the impact of $\mathrm{R} \& \mathrm{D}$, because the model does not capture disruptive innovations. Third, some countries have already made considerable progress on entry barrier reductions and have very large starting levels of R\&D tax credit rates. For these Member States, further reductions of entry barriers or further increases in tax credits are likely to yield small impacts, due to low marginal returns of continuous improvements. Fourth, there may be a discrepancy between the estimated entry barriers in the model and the actual entry costs faced by individual firms which depend on size, geographical location and other country-specific characteristics that the model does not account for. Finally, the version of QUEST III model used for the simulations is a three-country model characterising an individual Member State versus the EU27 and the rest of the world. Thus, the effects of potential simultaneous cross-country policies or spillovers generated by, for instance, common deregulation policies or the effect of tax competition cannot be studied. With these caveats in mind, as we are mainly interested in highlighting the macroeconomic factors impacting the effectiveness of the two R\&D policies discussed in the chapter, the cross-country comparison made below is yields interesting insights, not least because, as pointed out in BravoBiosca et al. (2013), it highlights the potential for further improvements across countries.

Moreover, to explain the cross-country differences in the results of the simulations it is key to understand the differences in the values of the structural parameters that capture the deep characteristics of the economy of each Member States. The most important structural parameters and variables, that affect the impact and transmission of shocks to entry barriers and tax credits, are summarised for each Member State in Table 9.1 .

\subsubsection{Reduction in Entry Barriers}

The first policy scenario discussed is a reduction in the value of fixed entry costs for intermediate firms equal to $0.1 \%$ of GDP (see Benedetti Fasil et al., 2017). ${ }^{9}$ In each simulation, the shock is applied to the fixed costs of a given country only; the other Member States and the rest of the world

\footnotetext{
${ }^{9}$ Even though the original entry barrier costs are calculated in GDP per capita terms in Djankov et al. (2008), all quantities in the model are expressed in terms of GDP (which is the numeraire). Hence the reason for the choice of the size of the shock in GDP terms instead of GDP per capita.
} 
Table 9.1 Cross-country values of selected parameters and initial steady-state values of key variables (QUEST calibration January 2017)

\begin{tabular}{lllllllll}
\hline & $F C_{A}$ & \multirow{2}{*}{$\tau^{A}$} & $\lambda$ & $v$ & $R \& D_{i n t}$ & $L_{A, 0}$ & $\varphi$ & $t^{K}$ \\
\hline AT & 0.063 & 0.119 & 0.398 & 0.213 & 0.034 & 0.012 & 0.619 & 0.250 \\
BE & 0.060 & 0.108 & 0.465 & 0.309 & 0.027 & 0.010 & 0.555 & 0.355 \\
BG & 0.054 & 0.126 & 0.645 & 1.282 & 0.009 & 0.004 & 0.386 & 0.235 \\
CY & 0.144 & 0.134 & 0.551 & 1.077 & 0.006 & 0.002 & 0.476 & 0.260 \\
CZ & 0.100 & 0.185 & 0.496 & 0.484 & 0.022 & 0.010 & 0.478 & 0.180 \\
DE & 0.048 & 0.010 & 0.496 & 0.298 & 0.032 & 0.012 & 0.548 & 0.222 \\
DK & 0.011 & 0.019 & 0.473 & 0.255 & 0.036 & 0.016 & 0.548 & 0.235 \\
EE & 0.022 & 0.139 & 0.482 & 0.416 & 0.016 & 0.007 & 0.542 & 0.081 \\
EL & 0.058 & 0.088 & 0.652 & 1.301 & 0.010 & 0.004 & 0.377 & 0.239 \\
ES & 0.090 & 0.276 & 0.777 & 1.745 & 0.014 & 0.007 & 0.257 & 0.253 \\
FI & 0.049 & 0.031 & 0.441 & 0.231 & 0.036 & 0.015 & 0.578 & 0.299 \\
FR & 0.019 & 0.232 & 0.526 & 0.404 & 0.026 & 0.010 & 0.497 & 0.469 \\
HR & 0.064 & 0.133 & 0.672 & 1.598 & 0.009 & 0.004 & 0.361 & 0.235 \\
HU & 0.084 & 0.156 & 0.595 & 0.776 & 0.016 & 0.006 & 0.435 & 0.214 \\
IE & 0.016 & 0.241 & 0.595 & 0.580 & 0.017 & 0.008 & 0.456 & 0.130 \\
IT & 0.153 & 0.049 & 0.777 & 1.752 & 0.015 & 0.007 & 0.257 & 0.370 \\
LT & 0.015 & 0.139 & 0.582 & 0.751 & 0.011 & 0.006 & 0.447 & 0.098 \\
LU & 0.046 & 0.020 & 0.594 & 0.659 & 0.008 & 0.008 & 0.432 & 0.239 \\
LV & 0.030 & 0.139 & 0.738 & 2.027 & 0.008 & 0.005 & 0.299 & 0.099 \\
MT & 0.179 & 0.135 & 0.773 & 2.091 & 0.009 & 0.006 & 0.265 & 0.235 \\
NL & 0.057 & 0.171 & 0.547 & 0.431 & 0.022 & 0.011 & 0.477 & 0.137 \\
PL & 0.196 & 0.022 & 0.542 & 0.738 & 0.011 & 0.004 & 0.684 & 0.190 \\
PT & 0.028 & 0.263 & 0.773 & 1.700 & 0.015 & 0.007 & 0.261 & 0.295 \\
RO & 0.041 & 0.126 & 0.879 & 7.658 & 0.004 & 0.002 & 0.164 & 0.235 \\
SE & 0.025 & 0.070 & 0.335 & 0.152 & 0.040 & 0.014 & 0.679 & 0.306 \\
SI & 0.016 & 0.159 & 0.477 & 0.331 & 0.028 & 0.011 & 0.546 & 0.196 \\
SK & 0.045 & 0.102 & 0.685 & 1.439 & 0.010 & 0.005 & 0.349 & 0.167 \\
UK & 0.013 & 0.166 & 0.495 & 0.363 & 0.019 & 0.010 & 0.527 & 0.357 \\
\hline & & & & & & & & \\
\hline
\end{tabular}

are only indirectly affected via trade and financial links. The following graphs show the impulse response functions (IRF) of GDP, employment and TFP for the 28 Member States (Figs. 9.1, 9.2, 9.3).

High entry barriers preclude some intermediate good-producing firms from entering the market. This results in a low demand for patents and a low level of intangible capital. Hence, the marginal productivity of intangible capital is higher than in an equilibrium with more patents, due to decreasing returns. Other things equal, a shock that reduces entry barriers 
Fig. 9.1 Response of GDP to a reduction in fixed costs equal to $0.1 \%$ of GDP

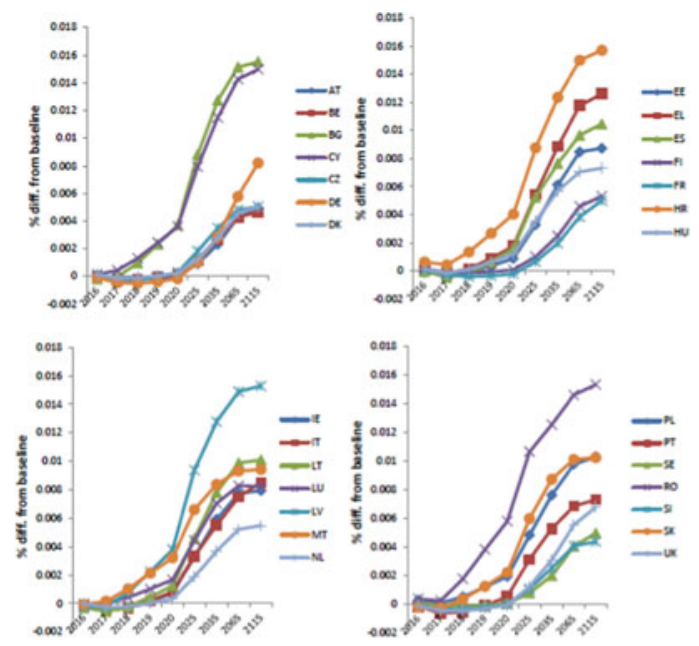

yields higher output effects the higher the marginal productivity of intangible capital, i.e., the higher the initial level of entry barriers. A symmetric argument, again owing to diminishing returns, holds for the share of research labour; a lower share of labour devoted to research means that the effect on output will be larger when entry barriers are reduced. In both cases the output effect is amplified by higher R\&D efficiency levels, and higher elasticities of R\&D with respect to researchers. Moreover, differences in the magnitude of impacts are better understood by investigating the role played by the different variables and parameters involved, particularly the ones reported in Table 9.1.

Poland, Malta and Italy exhibit the highest entry barriers among all countries, while also characterised by very low R\&D intensity and initial low quantity of researchers. The high marginal return on intangible capital and researchers' productivity results in a lower short-term reduction in GDP and in a long-term trajectory for output characterised by a higher slope compared to, for example, Slovenia and Portugal. As another example, the efficiency level of the Italian $\mathrm{R} \& \mathrm{D}$ production function, coupled with a relatively high value of the share of researchers in total labour, constitutes an advantage, as comparatively fewer researchers are needed to increase the production of knowledge, thereby relaxing the pressure on wages and sustaining a higher level of employment also in the long run. Nevertheless, due to comparatively higher wages in Italy, 
Fig. 9.2 Response of aggregate employment to a reduction in fixed costs equal to $0.1 \%$ of GDP

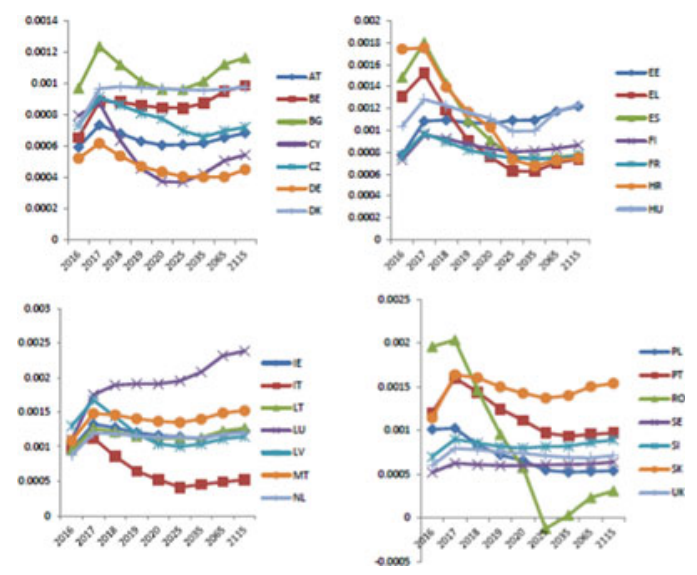

Italian TFP reacts to a lesser extent than Maltese and Polish TFP, leading to a slightly higher GDP response for Poland and Malta in the very long run.

Denmark is characterised by the lowest level of fixed costs and the highest share of initial research labour and R\&D intensity. Given this leadership position, a shock to fixed costs has only a marginal impact on GDP. Total employment reacts positively upon impact, mainly due to an increase in the share of low-and medium-skilled workers. The long-term effect on employment is however negligible. Also, the initial high share of R\&D employment mitigates the negative impact on GDP resulting from the reallocation of high-skilled labour from the final good sector to the R\&D sector. This also implies a comparatively moderate impact on TFP (see Fig. 9.3).

GDP and employment in Slovenia, Finland, Belgium, France and the Netherlands react only marginally to a shock on entry costs. Similar trajectories are also displayed by the Czech Republic, despite its higher entry costs. In this case, the reaction to the shock is hampered by a comparatively higher risk premium on investment in intangibles.

Portugal and Ireland, characterised by both fairly low entry costs and fairly low shares of research labour, display a steep long-run GDP trajectory, while TFP and employment react similarly to other countries. The effect of the positive long-run productivity effect of a reallocation of highskilled labour towards the research sector, which also causes the initial 

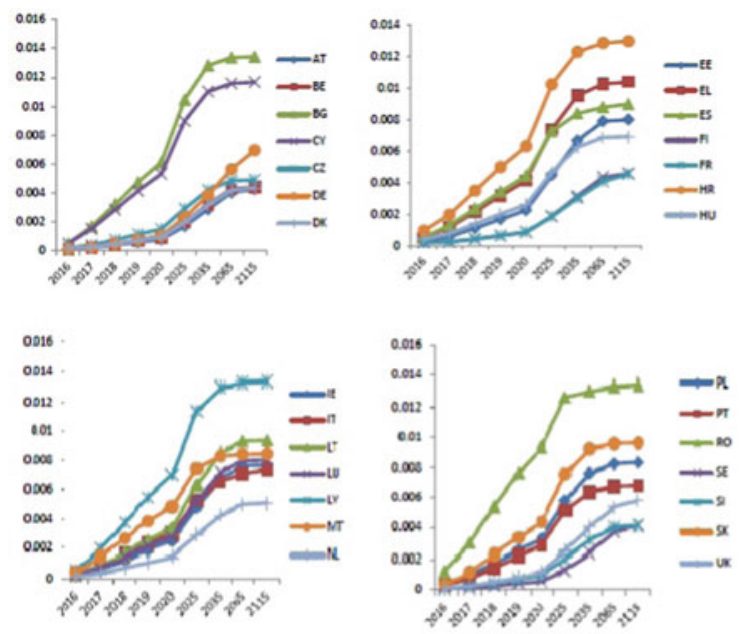

Fig. 9.3 Response of TFP to a reduction in fixed costs equal to $0.1 \%$ of GDP

drop in GDP, is hindered by a relatively high-risk premium. This slows down TFP growth, but sustains GDP as the final sector still benefits from a relatively higher number of skilled workers whose recruitment in the $\mathrm{R} \& \mathrm{D}$ sector is partially blocked by high-risk premia.

Slovakia and Lithuania have relatively low entry barriers and very low R\&D intensity and labour dedicated to research. On the other hand, they have a relatively high elasticity of $R \& D$ with respect to research labour and also display a relatively strong efficiency of the R\&D production function. Consequently, the transmission of the shock is amplified and exhibits trajectories similar to Malta and Poland, which start with much higher entry costs. The same reasoning holds for Spain, whose economy is characterised by fairly high entry costs, a fairly low share of researchers and $R \& D$ intensity, but an overall efficient R\&D technology.

Germany has a robust R\&D sector with a high initial R\&D intensity and share of research labour. A reduction in fixed costs, which are higher than the ones prevailing in Denmark, results in a positive longterm impact on GDP, TFP and employment. This is particularly strong after 20 years from the initial shock when the trajectories of TFP and GDP become the steepest among all countries, owing to the more important role played by structural factors such as the production technology. 
Romania is a particular case, with the lowest R\&D intensity and share of research labour employed in the R\&D sector together with fairly low initial entry costs. The high marginal returns to research labour, combined with a calibration of the R\&D production function that indicates an efficient use of inputs, draw skilled workers from the final good sector to the research sector. However, GDP reacts positively already in the short run as the strong short-run increase in TFP offsets the reallocation effect. As TFP increases, more low and medium-skilled workers are hired in the final good sector, and total employment reacts comparatively more than in other countries. Over time, upward pressure on wages substantially erodes the initial gains in employment.

\subsubsection{Increase in RED Tax Credits}

We proceed by simulating, for each Member State, the impact of a $0.1 \%$ of GDP permanent increase in tax credits for R\&D (see Sanchez-Martinez et al., 2017). ${ }^{10}$ By analysing the differences in outcomes for individual Member States we gain important insights into how different macroeconomic contexts influence the effectiveness of R\&D tax credits. Because of structural differences, the impact of such policy differs substantially across Member States. The following graphs show the deviations from baseline in the path followed by GDP, employment and TFP, over both the short-to-medium and long terms in all 28 Member States.

Inspection of Table 9.1 and the impulse response functions in Figs. 9.4, 9.5, and 9.6 reveals a number of important points. The effects of a more generous R\&D tax credit policy vary significantly across countries. A country that deserves special attention is Germany, as it is the only one without an initial tax credit policy in place. Germany's path for GDP exhibits a steep slope after 2025 . This can be explained by the trajectory for TFP, which is the ultimate precursor of income growth over the long term. In fact, it can be seen from Figures 9.4 and 9.6 that the evolution of GDP is a mirror image of that for TFP, and that the path for the latter variable is steepest also for Germany. The reason why Germany is able to reap larger benefits in the very long run compared to the rest of the EU

10 To be precise, the simulated shock consists of an increase in tax credit rates such that, for each country, the additional R\&D investment generated equals $0.1 \%$ of GDP (i.e. in the new scenario, tax-credited R\&D investment is $0.1 \%$ of GDP higher compared to baseline). 
Fig. 9.4 Response of GDP to an increase in the tax credit rate such that tax-credited additional $\mathrm{R} \& \mathrm{D}$ investment equals $0.1 \%$ of GDP
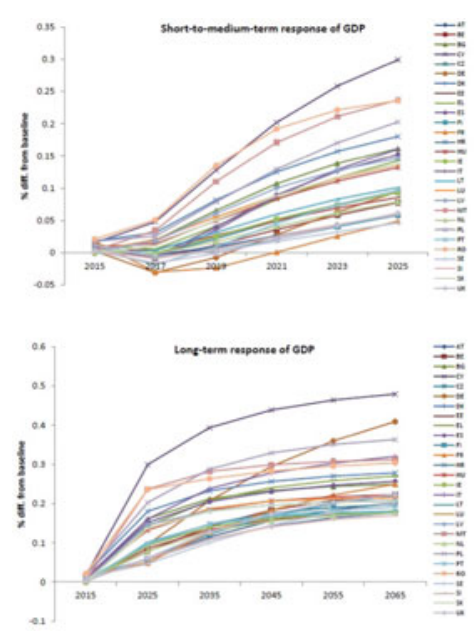

Fig. 9.5 Response of aggregate employment to an increase in the tax credit rate such that tax-credited additional $\mathrm{R} \& \mathrm{D}$ investment equals $0.1 \%$ of GDP

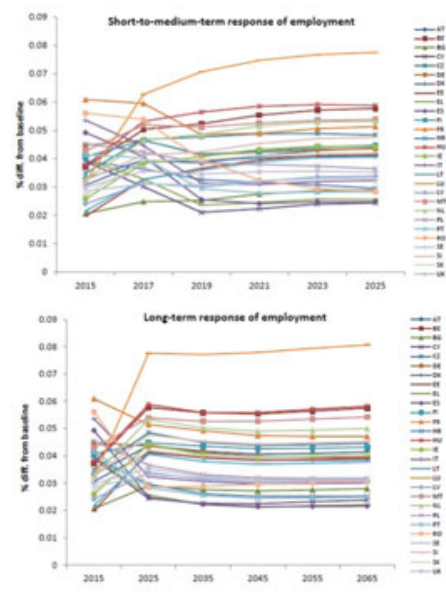

is that it departs from the highest levels in terms of the stock of knowledge and TFP among all Member States, thus being able to converge to a higher level of overall productivity in the new equilibrium. Because of the higher productivity and the bounded supply of all types of workers, real wages in Germany also reach the highest level among all countries in the long run. This deters the hiring of new workers to a greater extent than 
Fig. 9.6 Response of TFP to an increase in the tax credit rate such that tax-credited additional R\&D investment equals $0.1 \%$ of GDP
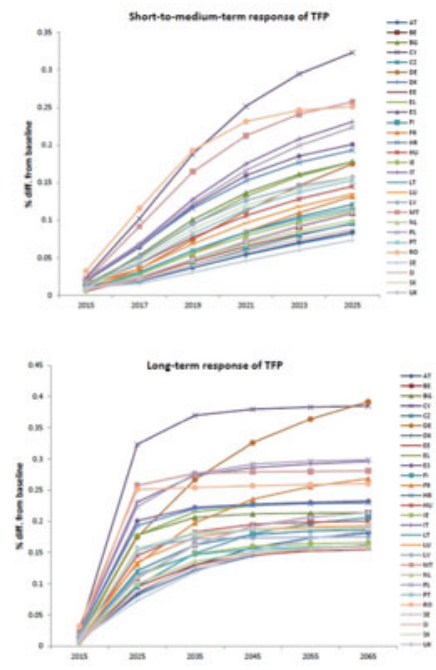

in other countries, and thus the rise observed in German employment in the long run is somewhat in the middle of the distribution of the size of employment effects in the sample of countries considered. Employment levels are boosted most strongly in Luxembourg, both in the short and medium-to-long terms, owing to a combination of factors, including relatively low increases in real wages.

France is another special country in the sample, as it exhibits the highest value of the $\mathrm{R} \& \mathrm{D}$ tax credit rate. As apparent from Figure 9.4, the initial response of GDP in France is among the most negative ones (along with Germany's), remaining subdued over the medium term and picking up only towards the longer term. This response in output mainly owes to the relatively more intense outflow of labour input from the final good production sector to the R\&D sector. The reason for this high sensitivity of employment to the policy shock is in turn partly related to the very high initial value for the capital income tax rate in France.

In short, the results of the simulations show that, by 2035, the countries which exhibit the largest GDP gains are Cyprus, Poland, Malta and Romania. These countries' R\&D intensities in the initial period are among the lowest relative to the other countries in the sample, which 
makes them experience larger changes, all else equal. ${ }^{11}$ However, this does not invalidate the fact that countries such as Italy and Cyprus, which depart from relatively sizeable levels of both R\&D intensity and the physical capital income tax rate, rank rather high in terms of the size of GDP impacts. This is especially true in the very long run, as the influence of the initial value for R\&D intensity fades away over time and deep parameters gain more importance. Also, these structural factors can partly offset the effect of the dissimilar magnitude of the tax credit shock across countries, even after only 20 years from now. This can be seen in the particular case of Italy. Despite departing from a middle-range value for R\&D intensity, relatively higher values of (i) the elasticity of R\&D output to the number of researchers, $\lambda$; (ii) the efficiency level of R\&D, $v$; and (iii) the capital income tax rate, yield a GDP impact in 2035 which is the fifth highest.

Therefore, we can conclude that deep parameters in the R\&D production function as well as policy parameters play a more important role for macroeconomic outcomes in the long run. By contrast, the starting level of variables such as R\&D intensity are more important determinants over the short to medium run. Our results and the explanations behind crosscountry differences in outcomes are thus consistent with the findings in D'Auria et al. (2009).

\subsection{Alternative Approaches to Modelling THE IMPACT OF R\&D TAX CREDITS AND ENTRY BARRIERS}

In this section, other modelling approaches aimed at addressing the problem of providing sound structural evaluations of the macroeconomic implications of policies, inducing changes in R\&D tax incentives and entry barriers in EU countries, is presented. This is an important challenge in view of, among other issues, the sluggish productivity performance of many European countries in the recent decades. First, a discussion is provided on some of the specific issues arising from the analyses presented in the last section. Based on this, a broader view on

11 Indeed, as discussed in DAuria et al. (2009), '...countries with low R\&D intensity (R\&D investment as a percentage of GDP and research labour, $L_{A}$ ) gain the most from $\mathrm{R} \& \mathrm{D}$ promoting policies. This is partly due to the fact that the $0.1 \%$ of GDP policymeasure implemented to boost the knowledge sector represents a proportionally stronger shock for countries investing less in R\&D and is proportionally smaller for the R\&D intensive countries...'. 
possible alternative and complementary lines of future research on this topic is suggested.

Growing availability of firm-level data in the last two decades has triggered a revolution in the field of international trade and is slowly changing the macroeconomic-modelling landscape. Long-run growth models have already started incorporating several dimensions of firm heterogeneity, but short-run models are still lagging behind. Most existing DSGE macroeconomic models do not embed firm heterogeneity, as the purpose they were originally designed for does not necessitate such structure. However, recent research shows that firm heterogeneity is particularly relevant for analysing the macroeconomic impact of innovation policies, such as the ones exemplified in the last sections on increasing R\&D tax credits and implementing measures to reducing market entry barriers (Acemoglu et al., 2017). For the purpose of policy evaluation exercises, it would be quite challenging to estimate/calibrate large-scale DSGE models with micro-data, since many EU countries still do not have high-quality data at a fine-grain level. With the growing availability of high-quality microdata, however, this could be a fruitful long-run avenue for future research. As a first step, it is interesting to explore the new potential channels brought about by new, smaller scale quantitative models featuring firm heterogeneity.

\subsubsection{The Treatment of RED Tax Credits and Subsidies}

Regarding the modelling of R\&D tax credits performed in SanchezMartinez et al. (2017), it is important to note that the growth engine embedded into the representative-firm DSGE model used is that of horizontal innovation (Romer, 1990), where growth is driven by the introduction of new products by new firms. Innovation is conducted by firms that were not producing before having discovered/invented and patented the new product. Hence, by construction, in this model incumbent firms do not innovate. Policy to stimulate innovation then must act on the entry margin, whereas tax credit is the appropriate policy only for incumbent firms. The authors circumvent this problem by interpreting the tax credit as acting on the cost to households of purchasing the patent resulting from innovation. The credit can then be seen as a subsidy to the acquisition of intangible capital (patents). This is an indirect way to introduce a tax subsidy in the model, which does not directly affect the firms' innovation decisions, but rather acts through the financial 
market affecting the user cost of (intangible) capital. It is not a priori clear whether this modelling choice leads to an under or overestimation of the effects of the R\&D tax credits, but it makes it virtually undistinguishable from a (physical) capital tax credit. A more direct way to model R\&D tax credits would be to use a Schumpeterian type of growth model, where innovation is performed by incumbent firms.

Furthermore, in the Romer class of models firms underinvest in innovation due to two types of dynamic inefficiencies. First, there exist knowledge spillovers and, second, there is a form of endogenously incomplete markets; there is no way to purchase a machine that is not yet produced, hence the set of Arrow-Debreu commodities is not complete, because it is endogenous. It follows that it is always optimal to subsidise innovation, and the model cannot accommodate cases of over-investment that can arise from strategic competition across firms. In policy debates, there is often no consensus on whether any type of investment should be subsidised. A quantitative economic framework where firms can potentially under or over-invest in R\&D depending on their own characteristics and on those of the sectors where they operate can address these issues, subject to the discipline imposed by the data. Schumpeterian models formalise the idea that firms compete vertically, so that successful innovation by one firm allows it to replace another firm. This process of creative destruction generates a negative externality in the form of overinvestment, as in its innovation decision the successful firm does not take into account the damage inflicted to other firms. In these models then, innovation subsidies can have a positive or negative economic impact depending on the characteristics of the sector and the economy. This class of models thus permits the analysis of those cases where the market produces too much innovation.

As an example of this family of macro models featuring firm dynamics, Akcigit et al. (2018) offer a model which belongs to the strand of research considering smaller size models compared to large DSGEs, focusing on a more detailed analysis of the macro and micro channels through which innovation policies affect aggregate outcomes. These models often depart from the representative firm framework to incorporate rich firm-level heterogeneity which is carefully calibrated to the data, thereby exploiting the wealth of microdata that has become available in recent decades. Some key papers in this literature are Akcigit and Kerr (2017), Acemoglu et al. (2017), and Akcigit et al. (2016), among others. 
In Akcigit et al. (2018), new evidence is provided using data from the US Patent Office of stronger competition experienced by American firms as a result of higher patenting by Japanese and European firms in most sectors of the economy during the 1970-1981 period. These developments, together with Reagan's introduction of R\&D subsidies at the time motivate the construction of a dynamic model of international technology competition, which is employed to perform a quantitative comparative analysis of the economic effects of that innovation policy vis-a-vis a counterfactual, protectionist policy. ${ }^{12}$

The model builds on step-by-step Schumpeterian innovation, which allows for strategic interaction among competitors. ${ }^{13}$ International markets are separated by transportation costs and tariff barriers. Slow international diffusion of ideas in the form of knowledge spillovers represents a potential engine of convergence across countries.

The model is calibrated to reproduce the convergence in patenting experienced by the United States in the 1970s and used to evaluate both the R\&D subsidy policy introduced in 1981 and an alternative, counterfactual, protectionist policy. The authors find that a 50\% increase in US import tariffs produces welfare gains for Americans lasting for about 20 years and losses afterwards. In the short run, trade barriers help firms in import-competing sectors recoup profitability sheltering them from foreign competition. This artificial protection reduces firms incentives to innovate which, in turn, impacts negatively the country's long-run growth prospects. This results hold under the assumption that US trade partners do not retaliate. Under retaliation, that is in the case where foreign countries exactly match the US policy change, even the short-run gains disappear. Figure 9.7 illustrates the results.

In Fig. 9.7 the welfare effects of the unilateral tariff and, in the second panel, the effect of the tariff on US incumbent firms' innovation, are shown. The Figure plots the incumbent firms' distribution of innovation in the steady state across technology gaps. Positive (negative) gaps illustrate technology classes (sectors) where US (foreign) firms hold a leading position in patenting. US firms accelerate their innovation efforts close to the import cut-off, the left peak before which their products' quality

12 This type of evaluation serves to illustrate how similar EU innovation policy evaluations could potentially be conducted based on this family of models.

13 The global economy is dominated by large and innovative firms (Bernard et al., 2017; Hottman et al., 2016) so that the strategic interaction between large firms is crucial. 


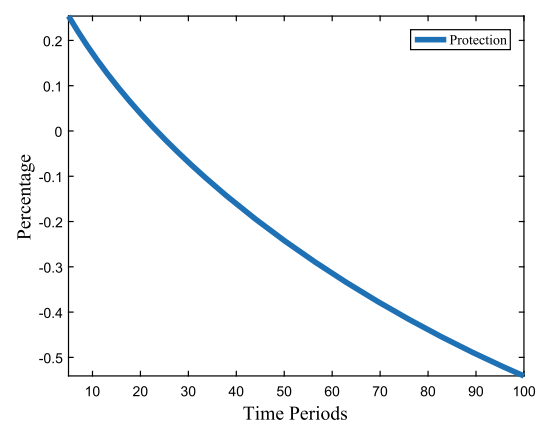

(a) Protectionist vs. benchmark welfare

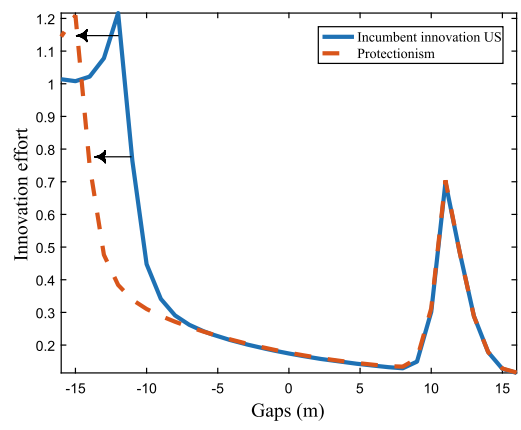

(b) Steady state incumbent innovation

Fig. 9.7 Unilateral 50\% increase in US trade tariffs (Akcigit et al., 2018)

is not high enough to beat foreign competitors on their own turf. The incentive to obtain more quality improvements and conquer the domestic market stimulates innovation. This effect is dubbed defensive innovation. American incumbent firms accelerate innovation also before entering the export market, the right peak. Here the incentive to go one step further is the conquest of the foreign market and it is dubbed the expansionary innovation effect. The increase in US tariff reduces the domestic cut-off, thereby allowing easier survival of US firms in their own market. This is the source of the short-run gains reported on the left panel of the Figures for the 20 years after the policy. In an imperfectly competitive world, tariff protection shifts profits (and in an extended version of the model also wages) away from foreign firms (and workers) towards US firms (and workers). The side-effect of protectionism is that US firms in the import competing industries reduce their innovation effort, thereby reducing the growth prospects of the US economy and leading to welfare losses in the long run.

Figure 9.8 reports the effect of a trade war, where a 50\% US tariff hike is met by a similar hike from their commercial partners. As it can be seen in the left panel, even the short-run gains now disappear, and protectionism becomes a bad policy even for very short-sighted policymakers. Moreover, comparing the magnitude of the effects in the scenarios with and without retaliation, the latter are one order of magnitude larger, ranging from about 1 to over $2 \%$ of consumption per year. The right panel shows the economic mechanism behind this results. Retaliation affects US 


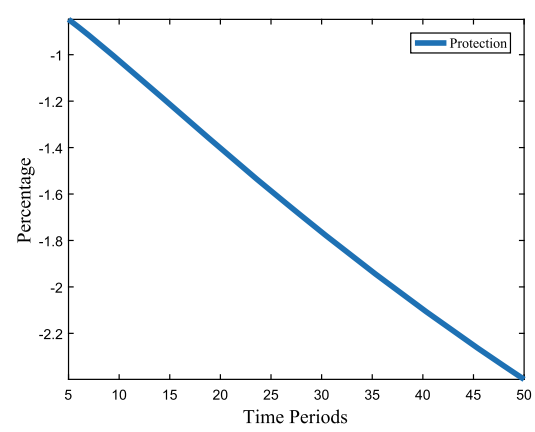

(a) Protectionist vs. benchmark welfare

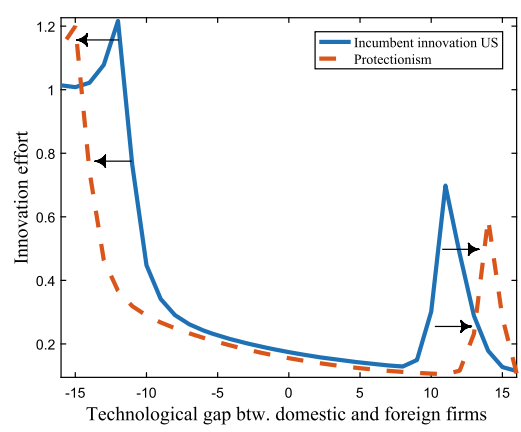

(b) Steady state incumbent innovation

Fig. 9.8 50 per cent increase in US trade tariffs under retaliation (Akcigit et al., 2018)

exporters, which find it harder to penetrate foreign markets. In the figure the export cut-off moves to the right, and some US firms exit the export market. Since American firms find it harder to compete in foreign markets, they are discouraged in their innovation efforts, which drops substantially for a large set of firms.

The R\&D subsidy change introduced in 1981 generates welfare gains both in the short and in the long run, as shown in Figure 9.9. Differently from the protectionist response, R\&D subsidies increase US incumbent

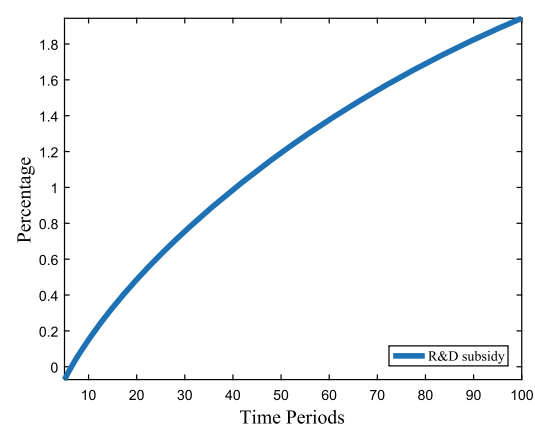

(a) Policy change vs. bench. welfare

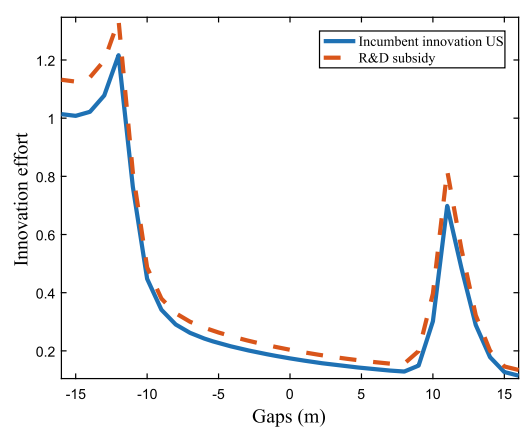

(b) Steady state incumbent innovation

Fig. 9.9 US R\&D subsidy increase in 1981 (Akcigit et al., 2018) 
firms' innovation in all sectors, thereby allowing policymakers to support national competitiveness without giving up the gains from trade. Welfare gains increase in time after the policy change as the growth effect of innovation has a stronger impact in the long run when the full potential of the innovation stimulus is realised.

Finally, Figure 9.10 shows the optimal US R\&D subsidy over different time horizons and in a 35 years horizon at different levels of multilateral openness. It follows from inspection of the Figure that longer policy horizons imply higher optimal R\&D subsidies, as a longer horizon allows larger gains from policy-induced growth to materialise. Moreover, more openness leads to lower optimal levels of innovation subsidies. Intuitively, a more open economy provides stronger incentives for US firms to innovate and there is less need for the government to subsidise innovation.

Although this model is more stylised along some dimensions than business-cycle DSGE models, it permits a clear illustration of some key mechanisms through which the R\&D subsidy policy operates. Moreover, it highlights the importance of the interaction between innovation policy and trade policy. The last result of the paper seems to suggest that the more integrated EU countries are (both in terms of tariff and non-tariff barriers) the weaker the need for a strong innovation subsidy policy. Moreover, for trade between EU countries and their non-EU trade partners, the results imply that any increase in trade barriers, due for

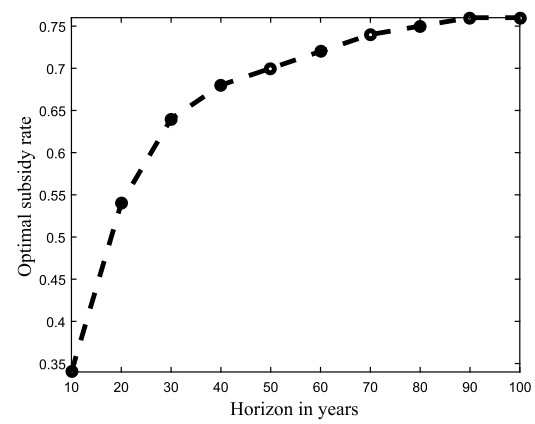

(a) Optimal subsidy over horizons

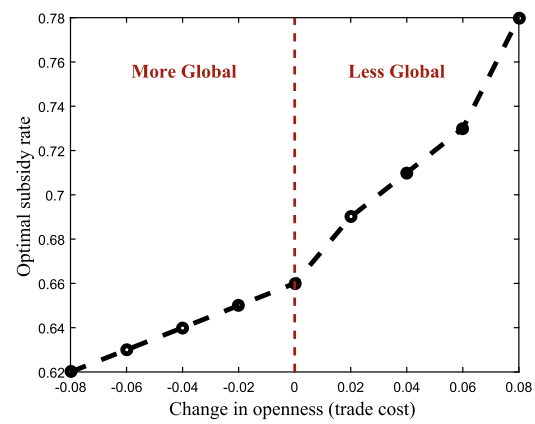

(b) Optimal subsidy over openness (35y h.)

Fig. 9.10 Optimal US R\&D subsidy, over different horizons and levels of openness (Akcigit et al., 2018) 
example to tariff wars, would increase the need for stronger EU support to innovation.

Another relevant example of the analysis of the impact of R\&D tax credits is presented in Borota et al. (2016). These authors analyse R\&D tax credit policies in the European Union via a multi-country Schumpeterian growth model,featuring cross-country technological heterogeneity. In technologically more advanced countries, firms have access to frontier production and innovation technologies, while less developed countries lag behind the frontier but can potentially catch up through technology diffusion and innovation. Countries may also differ in other dimensions such as size, human capital and other policies.

The authors first analyse the growth channels in the model, where different countries are integrated through trade and foreign direct investment, and explore the benefits and costs of R\&D tax incentives. Second, they identify and describe the optimal R\&D tax subsidy from each country's perspective, and from the perspective of the overall European economy. The latter identifies optimal policies under various scenarios of policy cooperation between countries. Policymakers may use R\&D tax incentives to promote the competitiveness of national firms in the global economy, at the expense of foreign firms. The strategic nature of this policy leads naturally to consider possible national and supra-national gains from cooperation. Since countries are different in this economy, costs and benefits from competition and cooperation in innovation policy differ across countries. A key point of the analysis is to show how countries' differences in size, technology and the level of economic integration within the EU, shape their incentives to set innovation policies cooperatively.

Evidence is presented showing that Western European firms' foreign direct investment to the East is strongly correlated with R\&D and innovation by Eastern European firms. In the model this is formalised as knowledge diffusion: when Western firms move their production to the east some of their technology spills over locally allowing local firms to start innovating and potentially leapfrogging Western firms. The incentives for FDI are driven by lower labour costs in the East, and the disincentives are related to technology diffusion that might allow local firms to imitate their technology and even leapfrog them. The paper looks at the R\&D subsidy game between Western European countries, bunched 
in a single region for simplicity, and a region of Eastern European countries. Moreover, the gains from innovation policy cooperation, defined as a unified subsidy at the European level, are also explored.

In this economy, as in the standard Schumpetarian model Aghion and Howitt (1992), the optimal subsidy is governed by two externalities, one leading to underinvestment and one to overinvestment in R\&D. First, once an innovation is introduced it benefits present and future consumers because future innovators build on it, this is the standing on the shoulder of gians type of externality, also known as the intertemporal spillover effect. Since innovating firms do not take these effects on consumers into account, they tend to underinvest in innovation and the intertemporal spillover generates a motive to subsidise R\&D. Second, when quality laggard firms successfully innovate, they drive incumbent leaders in their product lines out of business. The innovating firm does not take this into account and is therefore bound to overinvest in R\&D. The open economy dimensions of this model add a new key external effect. Successful Western innovation, for example, drives Eastern firms out of business and shifts profits towards the West, thereby increasing domestic income and welfare. Similarly, when an Eastern firm successfully innovates, it drives a Western firm out of business, and the related shift of profits across countries increase national welfare. Since home R\&D firms do not take this effect into account when innovating, a bias towards underinvestment obtains. This is the international business-stealing effect, and pins down the strategic motive for subsidising R\&D in an open economy. Table 9.2 summarises the results focusing on the long-run equilibrium of this economy.

The non-cooperation scenario is the one where each region sets its subsidy to maximise its own welfare given the other region's subsidy, and the result is the Nash equilibrium of this game. The cooperation equilibrium is obtained assuming that a European level planner sets a common

Table 9.2 The effect of cooperation

\begin{tabular}{lllllll}
\hline & $s^{W}$ & $s^{E}$ & $W^{W}$ & $W^{E}$ & $W^{E U}$ & growth \\
\hline Non-coop $\left(s_{n}^{W}, s_{n}^{E}\right)$ & 0.44 & 0.46 & 9.15 & 6.24 & 15.39 & 1.16 \\
Unified $\left(s_{\text {uni }}\right)$ & 0.78 & 0.78 & 8.84 & 7.45 & 16.29 & 3.23 \\
Welfare gain & & & -0.017 & 0.080 & 0.028 & \\
\hline
\end{tabular}


subsidy to maximise European welfare. The paper assumes that there is no ex-post scheme available to winners to compensate the losers. Therefore, cooperation will be implemented only when it benefits both regions.

Cooperation allows the internalisation of the international business stealing effect, neutralising the strategic role of subsidies. Cooperation leads to a higher level of subsidies compared to the non-cooperation scenario in both countries. Global growth rates are higher, as well as total European welfare. However, the West loses from cooperation and, in the absence of a compensation scheme, it does not have incentives to cooperate. Further simulations in the paper show that the incentives to cooperate for the West increase when the cost of offshoring production to the East declines. Intuitively, in a more integrated European market, Eastern firms represent more of a threat for Western firms, as cheaper offshoring increases technology transfer to the East thereby exposing Western firms to more intense technological competition.

This model adds hence a new perspective to the evaluation of R\&D subsidies. Accounting for strategic innovation policy competition across European countries provides a framework for evaluating a common EU R\&D tax policy.

\subsubsection{The Treatment of Entry Barriers}

As an example of an alternative approach to modelling the impact of a reduction in entry barriers, within the same family of models with heterogeneous firms, Impullitti and Licandro (2018) use a version of this type of model to assess the effects of both a reduction in entry costs and credit frictions. The model represents a two-country world with symmetric technologies, preferences and endowments, where both countries produce exactly the same set of differentiated goods which can be traded at an iceberg trade cost. Within a given variety, firms from both countries compete à la Cournot for market shares. At entry, firms draw a productivity level from a given distribution. After entry, they invest in innovation to increase their productivity. The innovation technology features within variety knowledge spillovers at the country level generating sustained growth under a stationary productivity distribution. In steady state, the productivity distribution permanently moves to the right as a travelling wave at the long-run growth rate. In what follows the analysis is restricted to the steady-state equilibrium. Notice that, as opposed to Romer-style endogenous growth models, the growth engine in this 
model comes from innovation by incumbent firms rather than entrants. Hence, policies affecting the cost of entry would impact growth only indirectly, through their effect on product market competition. Hence, all the mechanisms shown here are complementary to those present in representative-firm DSGE models.

The model is calibrated to match some key aggregate and firm-level facts of the US economy. These targets lay in rather standard ranges, and so their numerical values can be deemed as relevant for large EU countries too. The following exercises are performed: first, the effects of changing the entry cost parameter for a sufficiently wide range of values around the benchmark value is simulated. The effects on firm selection, markups, innovation, growth and welfare, are shown. In order to show the role of firm heterogeneity, the exercise is repeated, shutting down the selection channel. The second exercise is to reduce financial constraints on the fixed operating costs. Finally, notice that only policy changes implemented symmetrically in both countries are considered. This would be equivalent to a coordinated EU-level policy on entry barriers and credit constraints reductions in a EU-wide model such as QUEST III.

\subsubsection{Reducing Entry Barriers}

Figure 9.11 shows the effect of wide changes in the entry cost around the benchmark value which is 0.1 , corresponding to about $7 \%$ of GDP. Changes in key endogenous variables in the baseline model and in a version of the model where the selection effect is shut down are reported. That is, changes in policy parameters that affect the survival cut-off, which is set constant at the benchmark level, are assumed away. Hence, the economies with and without selection have by construction the same equilibrium at the benchmark entry cost.

The simulations show that a reduction in entry costs generates larger pro-competitive effects in the benchmark economy than in the economy without selection. When entry cost is reduced, the number of firms in each product line increases more and the average markups drops more in the baseline economy than in the economy without selection. Intuitively, lower entry costs induce more firms to enter the market, thereby reducing markups. Stronger product market competition forces the less productive, less profitable firms, out of the market, thereby generating tougher firm selection which leads to a lower firm survival probability. By contrast, in the model without selection firm survival is unchanged. The pro-competitive effect leads to higher market efficiency which in 

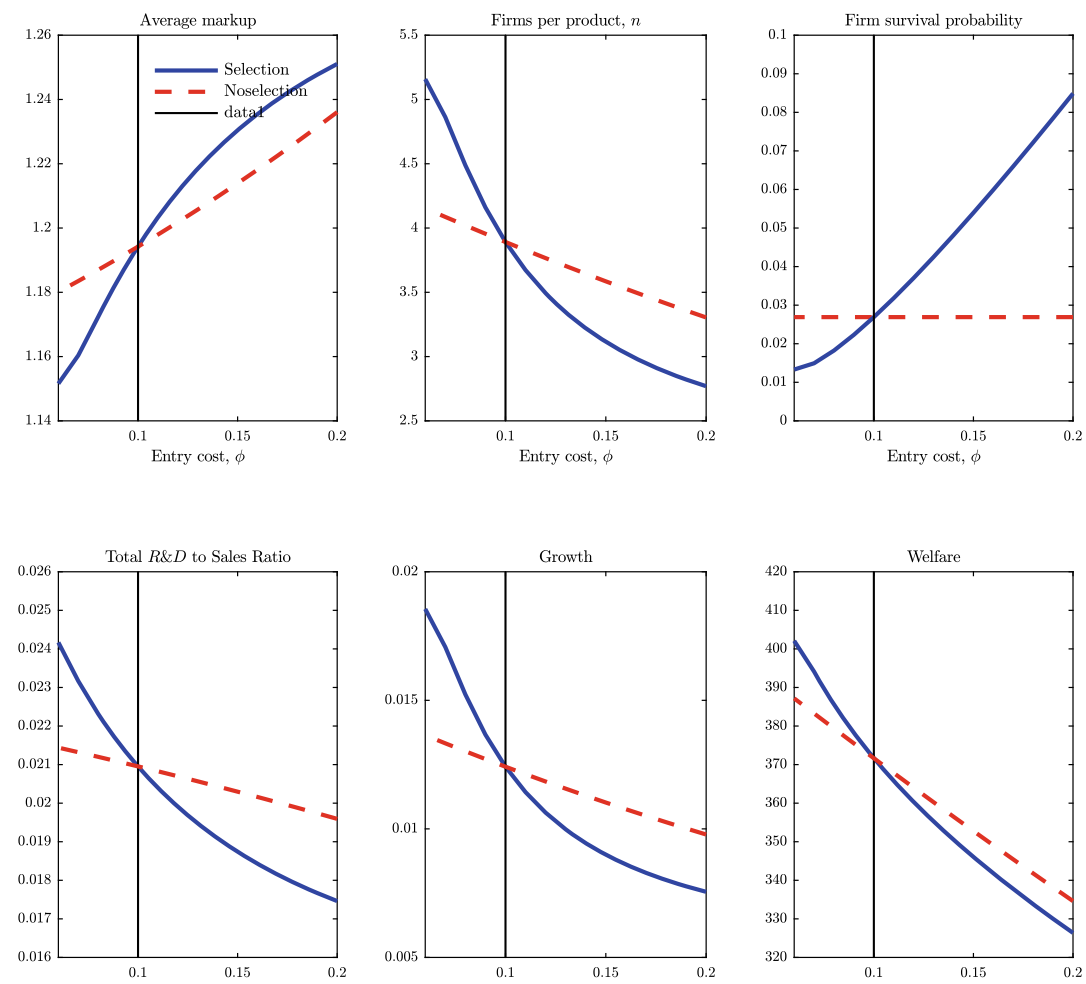

Fig. 9.11 Entry costs, selection and growth

turn yields a higher equilibrium size of the firms. In this economy, firms perform cost-reducing (or productivity-enhancing innovation), and the return to innovation scales with the quantity produced by the firm. Hence, a large firm size leads to greater innovation and faster productivity growth. The increase in firm size is feasible because of the presence of a homogenous good sector from which the more efficient differentiated good sector attracts resources. In the heterogeneous firm model there is an additional reallocation from exiting, less productive firms to surviving, more productive firms. This reallocation leads to higher incentives to innovate and faster productivity growth than in the model without selection. Finally, there are several channels of welfare gains in this economy. The economy without selection features welfare improvements from a 
reduction in entry costs coming from the reduction in markups, and the induced increase in productivity growth. The economy with selection adds additional static and dynamic gains due to the adjustments on the extensive margin. First, selection further increases the static efficiency of the economy; second, by stimulating innovation, it fuels an additional surge in long-run productivity growth.

\subsubsection{Reducing Financial Constraints}

The original model does not feature credit constraints but they can be easily introduced. In order to introduce credit constraints, it is assumed that while variable costs can be funded internally, firms must borrow a fraction $d \in(0,1)$ of their fixed operating costs $\lambda$ upfront. In order to cover this upfront cost, firms borrow from financial institutions pledging a fraction $\gamma \in(0,1)$ as collateral. ${ }^{14}$ Higher $d$ and lower $\gamma$ indicate stronger financial vulnerability of the firm or sector. Neither cross-sector nor crossfirm heterogeneity along this dimension is assumed for simplicity. Because of the imperfect ability to insure risk away, credit institutions can expect to be repaid by firms with probability $\chi \in(0,1)$, which embodies the strength of financial institutions or their willingness to enforce credit contracts. For simplicity, it is assumed that firms are credit constrained only in financing the fixed cost for producing domestically. ${ }^{15}$ To embed this credit friction, the firm's problem of the original model must be augmented with the following constraints:

$$
\begin{aligned}
& L C: \quad r\left(\tilde{z}_{t}\right)-h\left(\tilde{z}_{t}\right)-(1-d) \lambda \geq F\left(\tilde{z}_{t}\right), \\
& P C: \quad-d \lambda+\chi F\left(\tilde{z}_{t}\right)+(1-\chi) \gamma \lambda \geq 0,
\end{aligned}
$$

where $r\left(\tilde{z}_{t}\right)$ are the revenues net of variable production costs of a firm with productivity $\tilde{z}_{t}, h\left(\tilde{z}_{t}\right)$ is the R\&D expenditure, and $F(\tilde{z})$ is the payment due to the financial institution in case the contract is enforced. The liquidity constraint (LC) states that in case of repayment firms can pay up to their net revenues. The participation constraint (PC) implies that the financial institution is willing to enter the contract only if the expected

${ }^{14}$ In purchasing intermediate inputs, paying salaries to workers, and paying rents for land use and equipment, firms often have to incur in expenses previous to production and sales.

15 The model can be easily extended to include frictions on fixed export costs. 
returns exceed the outside option, which for simplicity is normalised to zero.

The optimal decision of firms is to adjust their payment $F$ to take the investors to their participation constraint, which in equilibrium holds with equality. Substituting this into the liquidity constraint (LC), the domestic survival cut-off of this economy can be determined. Focusing on the steady-state equilibrium, where $z$ is the stationary productivity level of firm $z$, the survival cut-off $z^{*}$ can be expressed as:

$$
r\left(z^{*}\right)-h\left(z^{*}\right)=\hat{\lambda}
$$

where $\hat{\lambda}=\left[1+\frac{1-\chi}{\chi}(d-\gamma)\right] \lambda$ is the effective fixed cost which includes the cost of borrowing in imperfect financial markets. A more financially constrained economy is one in which credit institutions are less likely to be repaid, $\gamma$ is low, and therefore offer firms contracts with high cost of credit which imply a high effective fixed cost. Hence, the effects of financial constraints in this economy can be analysed by focusing on the induced changes in the fixed operating cost they produce.

In Figure 9.12, the effects of wide changes in the fixed operating cost are simulated around the benchmark value which is 0.01 (corresponding to about $3.9 \%$ of GDP). A reduction in the fixed operating cost is shown to generate an anti-selection effect, that is it makes firm survival easier. In every model with firm heterogeneity, high fixed cost serves as a discipline devise since they make survival harder for less productive firms. Hence, the probability of firm survival increases as fixed costs decrease. In our model, more productive firms innovate more, and since higher survival rates leave firms with low productivity on the market, this leads to lower aggregate innovation and growth.

\subsubsection{Policy Comparison}

Table 9.3 reports some quantifications of the effects of the policy changes considered above, allowing for a direct comparison of their impact on key outcomes. First the effects of a $10 \%$ reduction in the entry cost are computed, from its benchmark value of 0.1 to 0.09 , a reduction equivalent to $0.7 \%$ of GDP. Although the markup declines only by one per cent, the selection effect is strong and reduces the probability of firm survival at entry by $18 \%$. The total R\&D to sales ratio increases by $3 \%$ and growth and welfare rise by about $9 \%$. Repeating the same exercise in the model without selection it can be seen that the effects are substantially smaller: 

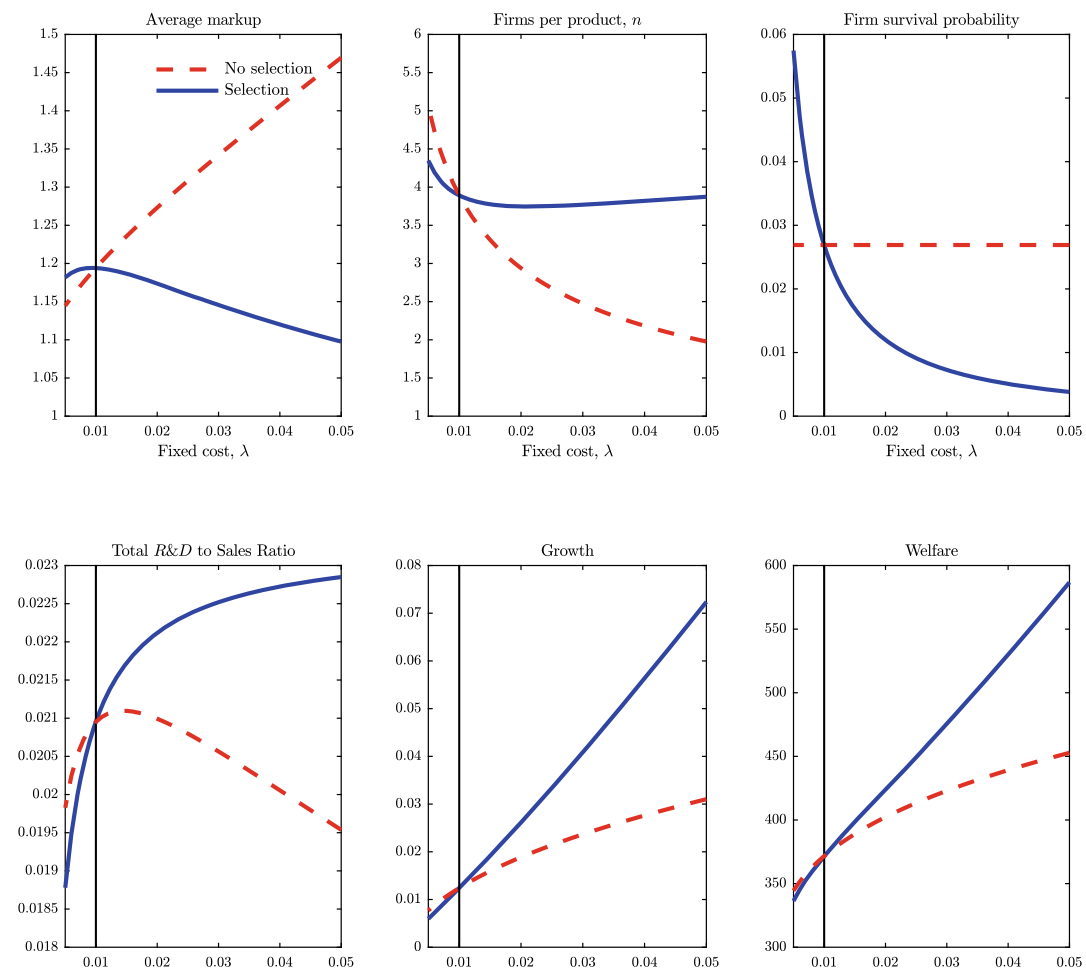

Fig. 9.12 Credit constraints, selection and growth: Domestic fixed cost

Table 9.3 Effect of a 10\% reduction in entry and fixed cost (percentage change)

\begin{tabular}{lcccc}
\hline \multicolumn{1}{c}{ Benchmark } & \multicolumn{3}{c}{ No selection } \\
\hline & $\Delta$ entry cost & $\Delta$ fixed cost & $\Delta$ entry cost & $\Delta$ fixed cost \\
Markup & -1 & 0.01 & -0.3 & -0.7 \\
Survival probability & -18.6 & 11.8 & 0 & 0 \\
R\&D/sales & 3 & -1.2 & 0.6 & -0.5 \\
Growth & 9.6 & -11.2 & 2.4 & -6.8 \\
Welfare gains & 9.1 & -7.5 & 5.2 & -5.6 \\
\hline
\end{tabular}


the growth effect is three times smaller than in the baseline model and the welfare effect is about half of that in the baseline model.

The effect of a $10 \%$ reduction in the fixed operating cost is also reported. In this case both models suggest non-negligible losses, but in line with the previous policy exercise, the losses when the selection channel is operative are substantially larger.

\subsubsection{Extensions}

Relaxing financial constraints to the fixed operating costs of producing domestically has a negative effect on growth as it makes the economy less selective. Different results can be obtained if the credit constraint is on the fixed operating cost. Proceeding as above, the credit friction leads to an effective fixed export cost of $\hat{\lambda_{x}}=\left[1+\frac{1-\chi}{\chi}(d-\gamma)\right] \lambda_{x}$. Figure 9.13 explores the effects of financial constraints on exports. A reduction in the fixed cost of exporting, triggered by a reduction in credit constraints, reduces the survival probability, therefore generating more selection, more innovation and faster growth. The economic mechanism is straightforward. Easier access to foreign markets allow marginal, non-exporting firms to start selling abroad, thereby boosting their sales and increasing their incentives to innovate. The productivity improvements made by these new exporters increase their competitiveness also on their domestic market where they see their market shares increase at the expense of the local non-exporting firms. As a consequence, the latter find it harder to survive and the least productive of them exit.

Finally notice that firms could also be credit constrained in financing their entry costs. The model can be easily extended to include this possibility. It could be assumed that firms borrow to finance the entire entry cost and that they face credit constraints on this activity. Financial institutions can expect to be paid the full firm profit with probability $\chi<1$, or only a fraction $t_{e} \in(0,1)$ of it with probability $1-\chi$. Free entry in the financial market leads to

$$
E_{z}(\phi(z))=\frac{\phi}{\chi+(1-\chi) t_{e}}=\hat{\phi}
$$

where $\hat{\phi}$ is the entry cost inclusive of the cost of borrowing, and $E_{z}(\phi(z))$ the expected profit at entry. Higher credit constraints imply higher cost of borrowing to finance entry and therefore higher entry costs. Policies aimed at improving firms' access to credit facilitate entry of new firms and, 

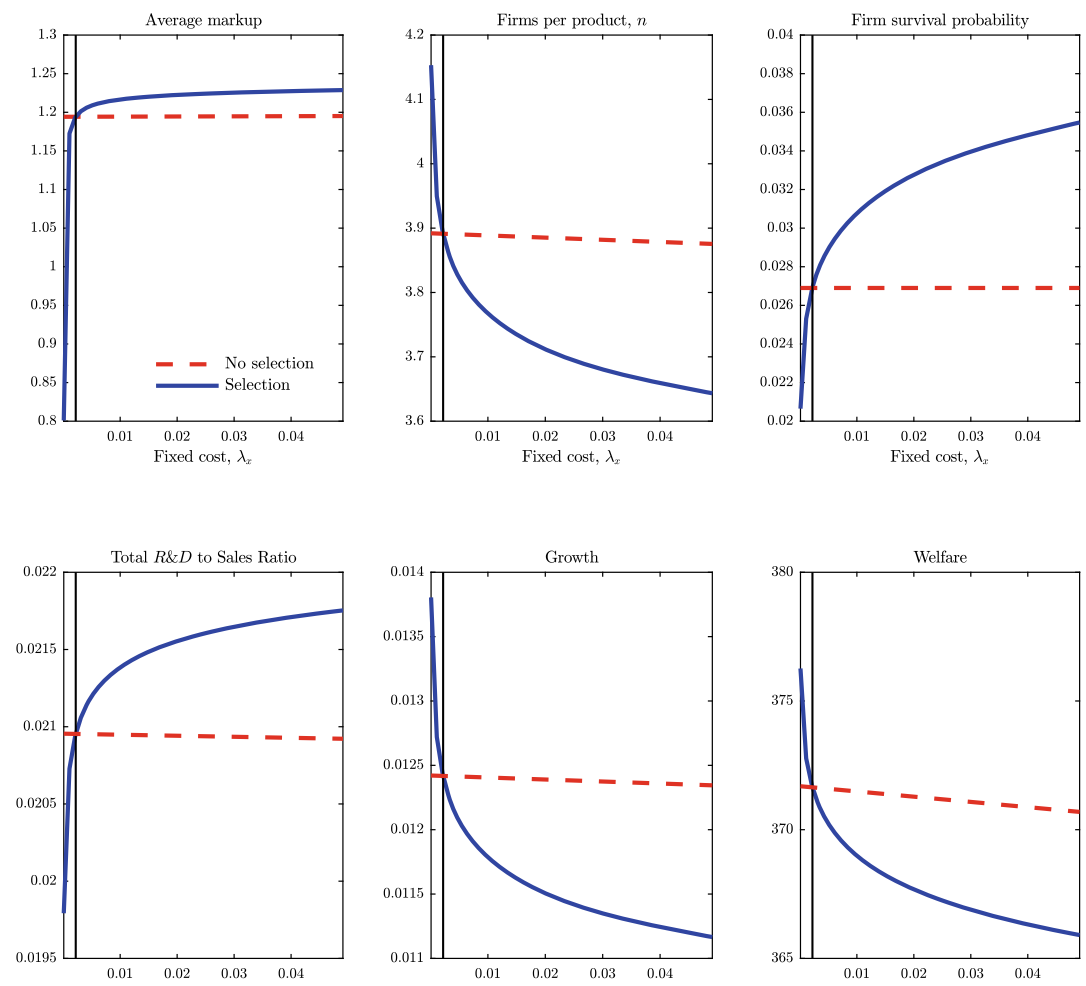

Fig. 9.13 Credit constraints, selection and growth: Export fixed cost

consequently, have the same impact on selection, innovation and growth as the reductions in entry costs are explored in Figure 9.11. Easier access to credit to finance entry leads to an economy that is more competitive, more selective and more innovative, resulting in a faster pace of aggregate growth and higher welfare.

\subsubsection{Conclusion}

A substantial share of the EU budget is directed at funding and bailing out incumbent (often large) firms (Acemoglu et al., 2017; Criscuolo et al., 2014). Recent frontier quantitative macroeconomic analysis of industrial policy has highlighted the importance of policies promoting selection and reallocation across firms with heterogeneous productivity 
and innovation capacity. Acemoglu et al. (2017) show that any horizontal policy aimed a stimulating production and/or innovation by all firms ultimately hinders selection and reallocation, as it facilitates survival of inefficient and non-innovative firms. The open economy dimension of the model that was used in the simple policy analysis above adds an important qualification to those results. Reducing credit constraints on non-exporting firms makes the economy less selective thereby hindering efficiency-improving reallocations of market shares towards more productive and more innovative firms. This is in line with Acemoglu et al.'s (2017) results. Lowering financial constraints on exporting firms, though, has the opposite effect, generating more selection, more reallocation and faster growth. This is a relevant guidance to avoid firm-specific or sectorspecific policies which are often open to 'pork-barrel' distortions. By facilitating access to credit to exporting firms, policymakers let the market pick the winners. The second conclusion that can be drawn from the experiments above is that slashing financial and non-financial barriers to entry has unambiguously positive effects on competition, selection and growth.

Relating the results here with the findings in Benedetti Fasil et al. (2017), a number of conclusions can be drawn: first, a reduction in entry barriers can affect innovation and growth even in a model where new firms are not a direct engine of growth; hence, this is a new channel complementing the one in Romer-type models. Second, endogenous markups allow entry policies to have substantial efficiency effects on the economy. Third, models that disregard firm heterogeneity and extensive margins of adjustment, both on the domestic and the export market, may underestimate the effects of entry and regulation policies on growth and welfare. Finally, financial incentives to incumbent firms have different implications for growth depending on whether they are directed to domestic or to exporting firms.

\section{REFERENCES}

Acemoglu, D., Akcigit, U., Alp, H., Bloom, N., \& Kerr, W. R. (2017). Innovation, reallocation and growth (National Bureau of Economic Research Working Paper 18993).

Aghion, P., \& Howitt, P. (1992). A model of growth through creative destruction. Econometrica, 60, 323-351. 
Akcigit, U., Hanley, D., \& Stantcheva, S. (2016). Optimal taxation and R\&D policies (National Bureau of Economic Research Working Paper 22908).

Akcigit, U., \& Kerr, W. R. (2017). Growth through heterogeneous innovations. Journal of Political Economy, 126(4), 1374-1443.

Akcigit, U., Sina, A., \& Impullitti, G. (2018). Innovation and trade policy in a globalizing world (NBER Working Paper No. 24543).

Benedetti Fasil, C., Sanchez-Martinez, M., Christensen, P., \& Robledo-Bottcher, N. (2017). Entry barriers and their macroeconomic impact in the EU: An assessment using QUEST III (JRC Technical Report EUR 28857 EN).

Bernard, A. B., Jensen, J. B., Redding, S. J., \& Schott, P. K. (2017). Global Firms. Journal of Economic Literature, 56(2), 565-619.

Borota, T., Defever, F., \& Impullitti, G. (2016). Innovation policy in an interdependent world: A European perspective. Mimeo.

Bravo-Biosca, A., Criscuolo, C., \& Menon, C. (2013). What drives the dynamics of business growth? (OECD Science, Technology and Industry Policy Papers, 1).

Cincera, M., \& Galgau, O. (2005). Impact of market entry and exit on EU productivity and growth performance (DG ECFIN, European EconomyEconomic Papers 2008-2015).

Ciriaci, D. (2014). Business dynamics and red tape barriers (DG ECFIN, European Economy. Economic Papers 432).

Criscuolo, C., Gal, P. N., \& Menon, C. (2014). The dynamics of employment growth: New evidence from 18 countries (NBER Working Papers 17842).

Criscuolo, C., Martin, R., Overman, H., \& Van Reene, J. (2014). The causal effects of an industrial policy (OECD Science, Technology and Industry Policy Papers No. 14).

D'Auria, F., Pagano, A., Ratto, M., \& Varga, J. (2009). A comparison of structural reform scenarios across the EU member states: Simulation-based analysis using the QUEST model with endogenous growth (DG ECFIN, European Economy. Economic Papers 392).

Djankov, S., La Porta, R., Lopez De Silanes, F., \& Shleifer, A. (2008). The regulation of entry: A survey (CEPR Discussion Papers 7080).

European Commission. (2003). Investing in research: An action plan for Europe (Communication from the Commission SEC/489/2003).

European Commission. (2013, December). Product market review 2013Financing the real economy: Annex 5 (DG ECFIN, European Economy $8)$.

Gabler, A., \& Licandro, O. (2009). Firm dynamics support the importance of the embodied question (CEPR Discussion Paper 7486).

Haltiwanger, J. R., Jarmin, S., \& Miranda, J. (2013). Who creates jobs? Small versus young. Review of Economics and Statistics, 95(2), 347-361. 
Hottman, C. J., Redding, S. J., \& Weinstein, D. E. (2016). Quantifying the sources of firm heterogeneity. Quarterly Journal of Economics, 131(3), 12911364.

Impullitti, G., \& Licandro, O. (2018). Trade, firm selection, and innovation: The competition channel. Economic Journal, 128, 189-229.

Luttmer, E. G. J. (2007). Selection and growth, and the size distribution of firms. Quarterly Journal of Economics, 122(3), 1103-1144.

Nicoletti, G., \& Scarpetta, S. (2003). Regulation, productivity and growth: OECD evidence (Policy Research Working Paper Series 2944).

OECD. (2014). OECD R\&D Tax Incentives Indicators. OECD-Directorate for Science, Technology and Innovation. Science, Technology and Industry Scoreboard.

OECD. (2015). OECD science, technology and industry scoreboard 2015: Innovation for growth and society (Technical Report, OECD). Directorate for Science, Technology and Innovation. Science, Technology and Industry Scoreboard.

Romer, P. M. (1990). Endogenous technological change. Journal of Political Economy, 98, 71-102.

Sanchez-Martinez, M., Benedetti Fasil, C., Christensen, P., \& Robledo-Bottcher, N. (2017). ReD tax credits and their macroeconomic impact in the EU: An assessment using QUEST III (JRC Technical Report, EUR 28858 EN).

Sapir, A. (2004). Structural reforms and economic growth in the EU: Is Lisbon the right agenda? (ULB Institutional Repository, 8126).

Scarpetta, S., Hemmings, P., Tressels, T., \& Woo, J. (2002). The role of policy and institutions for productivity and firm dynamics: Evidence from micro and industry data (OECD Economics Department Working Paper Series 329).

Veugelers, R. (2016). Getting the most from public ReD spending in times of austerity: Some insights from Simpatic analysis (Bruegel Working Paper, No. $1)$. 
Open Access This chapter is licensed under the terms of the Creative Commons Attribution 4.0 International License (http://creativecommons.org/licenses/ by $/ 4.0 /$ ), which permits use, sharing, adaptation, distribution and reproduction in any medium or format, as long as you give appropriate credit to the original author(s) and the source, provide a link to the Creative Commons license and indicate if changes were made.

The images or other third party material in this chapter are included in the chapter's Creative Commons license, unless indicated otherwise in a credit line to the material. If material is not included in the chapter's Creative Commons license and your intended use is not permitted by statutory regulation or exceeds the permitted use, you will need to obtain permission directly from the copyright holder.

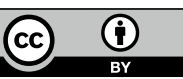

